\title{
Comparison of the Safety and Tolerance Profile of Micafungin with that of Other Echinocandins and Azoles in Patients with Pre-existing Child-Pugh B or C Liver Disease: A Case-Control Retrospective Study
}

\author{
Antonio Vena - Emilio Bouza - Matteo Bassetti · Francesco Menichetti - Maria Merelli • \\ Santiago Grau · Jesús Fortun · María Isabel Sánchez · José María Aguado • Paloma Merino • \\ Francisco Bonache $\cdot$ Patricia Muñoz
}

Received: October 14, 2019 / Published online: February 21, 2020

(C) The Author(s) 2020

\section{ABSTRACT}

Introduction: To assess the association between exposure to micafungin, other echinocandins, or azoles and the development of short-term liver injury (STLI) or long-term liver injury (LTLI) in patients with Child-Pugh B or C liver disease.

Methods: Multicenter case-control study of patients with Child-Pugh B or Cliver disease who received antifungals (AF) for $\geq 72 \mathrm{~h}$ (May 2009-May 2015) in six Spanish and Italian

Enhanced digital features To view enhanced digital features for this article go to https://doi.org/10.6084/ m9.figshare.11550816.

Electronic supplementary material The online version of this article (https://doi.org/10.1007/s40121020-00282-w) contains supplementary material, which is available to authorized users.

A. Vena $\cdot$ E. Bouza $\cdot$ F. Bonache $\cdot$ P. Muñoz $(\square)$ Clinical Microbiology and Infectious Diseases, Hospital General Universitario Gregorio Marañón, Madrid, Spain

e-mail: pmunoz@micro.hggm.es

A. Vena $\cdot$ E. Bouza $\cdot$ P. Muñoz

Instituto de Investigación Sanitaria Hospital

Gregorio Marañón, Madrid, Spain

E. Bouza · P. Muñoz

CIBER Enfermedades Respiratorias-CIBERES (CB06/

06/0058), Madrid, Spain

A. Vena · E. Bouza · J. M. Aguado · P. Muñoz Medicine Department, School of Medicine,

Universidad Complutense de Madrid, Madrid, Spain hospitals. All micafungin patients were randomly matched with one patient who received another echinocandin and with one patient who received azole treatment. Primary outcome was development of STLI or LTLI (development of any type of liver tumor during the follow-up period).

Results: Of 2335 patients with chronic liver disease admitted to the six centers, $20(0.85 \%)$ were found to have Child-Pugh $\mathrm{B}$ or $\mathrm{C}$ liver disease and received micafungin for $\geq 72 \mathrm{~h}$. During AF treatment, the frequency of STLI was $10 \%$ in each group. Most cases of STLI were asymptomatic, and AFs had to be switched to another class of AF in only two patients (one micafungin and one azole). No patients developed acute liver insufficiency, were admitted to the ICU, or had to undergo transplantation. Follow-up data (median of 1.3 years) were

A. Vena $\cdot$ M. Bassetti $\cdot$ M. Merelli

Infectious Diseases Clinic, Department of Medicine, University of Udine and Azienda Sanitaria

Universitaria Integrata, Udine, Italy

\section{A. Vena $\cdot$ M. Bassetti}

Department of Health Sciences, Infectious Disease

Clinic, University of Genoa and Hospital Policlinico

San Martino-IRCCS, Genoa, Italy

F. Menichetti

Infectious Diseases Clinic, Nuovo Santa Chiara

University Hospital, Azienda Ospedaliera

Universitaria Pisana, Pisa, Italy 
available for 30 patients. LTLI was observed in only one patient, who had previously received treatment with azoles.

Conclusions: Our study suggests that the administration of micafungin to patients with end-stage liver disease does not imply a higher risk of developing STLI or LTLI.

Keywords: End-stage liver disease; Liver injury; Micafungin; Safety

\section{Key Summary Points}

Patients with end-stage liver disease (ESLD) are at high risk of invasive fungal infections.

Information on the efficacy and safety of micafungin compared with other antifungals in ESLD patients is scarce.

The administration of micafungin to patients with ESLD was safe and did not imply a higher risk of developing short- or long-term liver injury.

\section{INTRODUCTION}

Patients with end-stage liver disease (ESLD) are at high risk of acquiring invasive fungal infections (IFI) because of alterations in gut

\section{S. Grau}

Department of Pharmacy, Hospital del Mar,

Universitat Autònoma de Barcelona, Barcelona, Spain

\section{J. Fortun}

Infectious Diseases Department, Hospital

Universitario Ramón y Cajal, Madrid, Spain

M. I. Sánchez

Clinical Microbiology and Infectious Diseases Department, Hospital Puerta de Hierro, Madrid, Spain

\section{J. M. Aguado}

Unit of Infectious Diseases, Hospital Universitario

'12 de Octubre', Madrid, Spain

P. Merino

Clinical Microbiology Department, Hospital

Universitario Clinico San Carlos, Madrid, Spain microbiota, gut permeability, and immune dysfunction $[1,2]$. The frequency of IFI in ESLD patients ranges from 1 to $10 \%[3,4]$, and development of IFI has a profound effect on the outcome of ESLD $[5,6]$.

Echinocandins are among the better tolerated antifungals in patients with ESLD [7-14]. Nevertheless, micafungin is the only echinocandin not approved in patients with ESLD because of an EMA warning on the potential development of liver tumors, as shown in preclinical studies in rats treated with high micafungin doses for either 3 or 6 months.

In humans, data on hepatotoxicity in patients treated with micafungin are scarce [15-21] and, to our knowledge, only three studies have partially evaluated this issue among ESLD patients [12-14]. However, data on the incidence of long-term liver injury (LTLI) and the relative magnitude of this risk compared with other antifungals have not been reported.

We performed a large, multicenter, case-control study in order to define, in routine clinical practice, the association between exposure to micafungin, other echinocandins, or azoles, and the development of short-term liver injury (STLI) or LTLI in a population of patients with pre-existing Child-Pugh B or C ESLD.

\section{MATERIALS AND METHODS}

\section{Study Design and Setting}

We performed a retrospective, multicenter, case-control study in six large tertiary-care hospitals in Spain and Italy. The study cohort consisted of adult patients with chronic Child-Pugh B or C ESLD [22] who received $\geq 72 \mathrm{~h}$ of therapy with micafungin, other echinocandins, or azoles from May 2009 to May 2015.

In order to avoid bias, cases were identified in each institution based on the diagnosis and procedure codes of the International Classification of Disease, Ninth Revision, Clinical Modification (ICD-9-CM). Patients with a primary and secondary diagnosis of chronic liver disease (ICD-9-CM codes used for that purpose are listed within the electronic supplementary 
material) were identified. Data were crosschecked with pharmacy databases consisting of all patients who received an echinocandin or an azole during the study period. Information on etiology, severity of liver disease, and antifungal exposure were then re-checked using the clinical charts.

\section{Inclusion Criteria}

To be considered cases, patients had to meet all of the following criteria: (1) ESLD classified as Child-Pugh B or C [22] on the first day that antifungal therapy was started; (2) micafungin at $100 \mathrm{mg}$ daily for at least $72 \mathrm{~h}$; and (3) prior and subsequent measurement of liver function.

For each case, we selected two matched controls: one receiving another class of echinocandins (caspofungin loading dose of $70 / 50 \mathrm{mg}$ followed by $50 / 35 \mathrm{mg}$ once daily or anidulafungin loading dose of $200 \mathrm{mg}$ then $100 \mathrm{mg}$ once daily) and one receiving an azole (fluconazole $400 \mathrm{mg}$ once daily or voriconazole loading dose of $6 \mathrm{mg} / \mathrm{kg}$ then $4 \mathrm{mg} / \mathrm{kg}$ twice daily). To be considered matched controls, patients had to be Child-Pugh B or C ESLD and fulfill the following conditions: (1) same sex; (2) antifungal therapy at about the same time as the case; (3) antifungal therapy with the same indication as the case (empirical or targeted treatment); and (4) survival for as long as the case after administration of antifungal drugs.

Patients who underwent liver transplantation were eligible for the study only if the graft was affected by a chronic disease (i.e., patient with recurrence of $\mathrm{HCV}$ cirrhosis after liver transplant). For both cases and controls, the index date was defined as the date of the first administration of the study drug.

\section{Follow-Up and Outcomes}

Outcomes were assessed during a follow-up period that began on the index date and ended on the date of death or the last clinical visit until the end of June 2016.

The primary outcome of the study was the incidence of short- or long-term toxicity in patients with Child-Pugh B or C ESLD. STLI was defined as an increase during antifungal treatment in transaminase levels to $>3$ times the upper limit of normal for patients who started antifungal therapy with normal liver function. If patients started antifungal treatment with abnormal baseline transaminase levels (i.e., $>50 \%$ greater than the upper limit of normal), STLI was defined as a doubling of the baseline transaminase level. LTLI was defined as the development of any type of liver tumor during the follow-up period.

Secondary outcomes were cumulative incidence of patients stopping treatment owing to abnormal liver function, cumulative incidence of patients needing transplantation owing to hepatotoxicity, re-admission for any cause in the following year, and number of episodes of ascitic decompensation or gastrointestinal bleeding during the following year.

\section{Clinical Data}

Data collected included demographic data, etiology of liver disease, underlying disease, and clinical course. When available, laboratory data were collected at days $-7,-3,0,+1,+3,+5$, $+7,+14,+28,+45,+60,+120$, and +180 and included the international normalized ratio, aspartate aminotransferase (AST), alanine aminotransferase (ALT), alkaline phosphatase, total bilirubin, gamma glutamyl transferase, creatinine, and albumin. Detailed data were also collected on concomitant drugs, type of invasive fungal infection, and pathogens.

\section{Ethics}

The study was approved by the institutional review board of the coordinating center (Hospital General Universitario Gregorio Marañón, MICRO.HGUGM.2014-017) and was in accordance with the declaration of Helsinki. Informed consent was deemed unnecessary due to the retrospective nature of the study.

\section{Statistical Analysis}

Patients who received micafungin were compared with those who received other 
echinocandins or azoles. To detect significant differences between groups, we used the Chi square test or Fisher exact test for categorical variables and a 2-tailed $t$ test or Mann-Whitney test for continuous variables, when appropriate. Values are expressed as mean \pm standard deviation (continuous variables) or as percentages of the group from which they were derived (categorical variable).

A multivariable logistic regression analysis was performed to assess risk factors for STLI. Variables associated with the development of STLI in the univariate analysis $(P$ value $\leq 0.3)$ were selected for possible inclusion. Statistical significance was set at $P<0.05$. The results were analyzed using SPSS, v.17.0 (SPSS, Chicago, IL, USA).

\section{RESULTS}

Between May 2009 and May 2015 (6 years), 2335 patients with a diagnosis of chronic liver disease were admitted to the six study centers (Hospital General Universitario Gregorio Marañón, 537 patients; Nuovo Santa Chiara University Hospital, 520; Santa Maria Misericordia Hospital, 450; Hospital Universitario Ramón y Cajal, 400; Hospital Puerta de Hierro, 260; and Hospital del Mar, 168). Of these, 20 patients who fulfilled the criteria of Child-Pugh $\mathrm{B}$ or $\mathrm{C}$ liver disease received micafungin for $\geq 72 \mathrm{~h}$. Overall, patients receiving micafungin represented $0.85 \%$ of all those with a diagnosis of chronic liver disease.

\section{Comparison of ESLD Patients Receiving Micafungin with Those Treated with Other Echinocandins or Azoles}

The demographics and baseline characteristics of the three groups (20 patients each) selected for the case-control study are summarized in Table 1. Univariate analysis revealed no significant differences between cases and controls regarding etiology of liver disease, other comorbidities, previous antibiotic therapy, and rate of cirrhosis-related complications. However, when compared with patients who received azoles, those with micafungin and other echinocandins had a higher MELD score and a higher Child-Pugh score. No differences were detected between patients who received micafungin and other echinocandins, although those with micafungin were significantly older (61.2 vs. 52.8 years, $P=0.01$ ).

\section{Comparison Between STLI and LTLI}

Exposure to antifungal treatment is reported in Table 1. Antifungals were mostly administered as targeted therapy against Candida spp. (60\%). The most frequent indications for antifungal treatment were bloodstream infections (33.3\%) and urinary tract infections (10\%), with no significant differences between groups. Length of therapy was significantly longer among patients receiving azoles (mean duration 19.2 days) than among those treated with micafungin (12.3 days) or other echinocandins (10.9 days). In contrast, compared to azoles, septic shock was more frequent in patients who received micafungin ( $35 \%$ vs. $0 \%, p=0.08)$ or other echinocandins ( $50 \%$ vs. $0 \%, p=0.03)$.

Six of 60 patients $(10 \%)$ patients developed STLI: two patients with micafungin, two patients with other echinocandins, and two patients with azoles. The rate of STLI was 0.81 cases per 100 patient-days for micafungin, 0.91 cases per 100 patient-days for other echinocandins, and 0.51 cases per 100 patient-days for azoles.

The increase in serum aminotransferase was asymptomatic in all patients who experienced STLI, and antifungal discontinuation was required in only two cases: one patient who was receiving micafungin and another who was receiving azoles. Figure 1 shows how laboratory values changed over time. There were no relevant differences in liver function over time between the groups. Interestingly, in all evaluable patients, transaminase levels returned to normal after withdrawal or switching of antifungal therapy. No patients developed acute liver insufficiency requiring ICU admission or liver transplantation.

Overall, in-hospital mortality was 35\% for cases treated with micafungin, $45 \%$ for other echinocandins, and $25 \%$ for azoles $(p=0.39)$. 
Table 1 Clinical characteristics of the study population and exposure to antifungal treatment

\begin{tabular}{|c|c|c|c|c|c|}
\hline Characteristics & Total $n=60$ & $\begin{array}{l}\text { Micafungin } \\
n=20\end{array}$ & $\begin{array}{l}\text { Other } \\
\text { echinocandins } \\
n=20\end{array}$ & $\begin{array}{l}\text { Azoles } \\
n=20\end{array}$ & $p$ \\
\hline Age (years) $($ mean $\pm S D)$ & $58.2 \pm 14.5$ & $61.2 \pm 11.2$ & $52.8 \pm 9.6$ & $60.6 \pm 20.1$ & 0.13 \\
\hline Male sex & $45(75.0)$ & $15(75.0)$ & $15(75.0)$ & $15(75.0)$ & 1 \\
\hline \multicolumn{6}{|l|}{ Race } \\
\hline White & $59(98.3)$ & $20(100)$ & $20(100)$ & $19(95.0)$ & 1 \\
\hline Non-white & $1(1.7)$ & 0 & 0 & $1(5.0)$ & \\
\hline \multicolumn{6}{|l|}{ Pre-existing liver disease } \\
\hline $\mathrm{HCV}$-associated cirrhosis & $26(43.3)$ & $7(35.0)$ & $12(60.0)$ & $7(35.0)$ & 0.64 \\
\hline $\mathrm{HBV}$-associated cirrhosis & $7(11.6)$ & $3(15.0)$ & $1(5.0)$ & $3(15.0)$ & 0.11 \\
\hline Alcohol-associated cirrhosis & $18(30.0)$ & $7(35.0)$ & $5(25.0)$ & $6(30.0)$ & 0.52 \\
\hline Cryptogenic cirrhosis & $4(6.6)$ & 0 & $1(5.0)$ & $3(15.0)$ & 0.78 \\
\hline Hepatocellular carcinoma & $8(13.3)$ & $2(10.0)$ & $4(20.0)$ & $2(20.0)$ & 0.15 \\
\hline Other causes ${ }^{a}$ & $7(11.6)$ & $3(15.0)$ & $3(15.0)$ & $1(5.0)$ & 0.56 \\
\hline Baseline MELD score & $17.7 \pm 7.3$ & $18.6 \pm 7.6$ & $19.6 \pm 5.8$ & $14.9 \pm 7.9$ & 0.10 \\
\hline Baseline child-pugh class B & $35(58.3)$ & $12(60.0)$ & $8(40.0)$ & $15(75.0)$ & 0.08 \\
\hline Baseline child-pugh class $\mathrm{C}$ & $25(41.6)$ & $8(40.0)$ & $12(60.0)$ & $5(25.0)$ & 0.08 \\
\hline Baseline child-pugh score & $9.1 \pm 1.4$ & $9.1 \pm 1.4$ & $9.6 \pm 1.2$ & $8.6 \pm 9.1$ & 0.07 \\
\hline \multicolumn{6}{|l|}{ Complications within previous year } \\
\hline Episode of ascites & $17(28.3)$ & $5(25.0)$ & $8(40.0)$ & $4(20.0)$ & 0.34 \\
\hline Episodes of gastrointestinal bleeding & $5(8.3)$ & $1(5.0)$ & $2(10.0)$ & $2(10.0)$ & 0.80 \\
\hline Antibiotic exposure & $46(76.6)$ & $14(70.0)$ & $18(90.0)$ & $14(70.0)$ & 0.22 \\
\hline \multicolumn{6}{|l|}{ Other comorbidities } \\
\hline Heart failure & $6(10.0)$ & $3(15.0)$ & $2(10.0)$ & $1(5.0)$ & 0.57 \\
\hline Renal chronic disease & $12(20.0)$ & $4(20.0)$ & $6(30.0)$ & $2(10.0)$ & 0.28 \\
\hline Respiratory disease & $7(11.6)$ & $3(15.0)$ & $2(10.0)$ & $2(10.0)$ & 0.85 \\
\hline Diabetes mellitus & $16(26.6)$ & $8(40.0)$ & $6(30.0)$ & $2(10.0)$ & 0.09 \\
\hline Cancer & $12(20.0)$ & $6(30.0)$ & $3(15.0)$ & $3(15.0)$ & 0.39 \\
\hline HIV infection & $5(8.3)$ & $3(15.0)$ & $1(5.0)$ & $1(5.0)$ & 0.41 \\
\hline \multicolumn{6}{|l|}{ Reason for starting AF therapy } \\
\hline Empirical therapy & $24(40.0)$ & $10(50.0)$ & $9(45.0)$ & $5(25.0)$ & 0.23 \\
\hline Targeted therapy & $36(60.0)$ & $10(50.0)$ & $11(55.0)$ & $15(75.0)$ & \\
\hline
\end{tabular}


Table 1 continued

\begin{tabular}{|c|c|c|c|c|c|}
\hline Characteristics & Total $n=60$ & $\begin{array}{l}\text { Micafungin } \\
n=20\end{array}$ & $\begin{array}{l}\text { Other } \\
\text { echinocandins } \\
n=20\end{array}$ & $\begin{array}{l}\text { Azoles } \\
n=20\end{array}$ & $p$ \\
\hline Length of AF treatment (median, range) & $14.1 \pm 8.0$ & $12.3 \pm 6.5$ & $10.9 \pm 5.6$ & $19.2 \pm 9.1$ & $<0.001$ \\
\hline \multicolumn{6}{|l|}{ Invasive fungal infection } \\
\hline Bloodstream infection & $20(33.3)$ & $5(50.0)$ & $6(54.5)$ & $9(60.0)$ & 0.88 \\
\hline Abdominal infection & $5(8.3)$ & $2(20.0)$ & 0 & $3(20)$ & 0.13 \\
\hline Urinary tract & $6(10.0)$ & $2(20.0)$ & $2(18.9)$ & $2(13.3)$ & 0.89 \\
\hline Lung & $2(3.3)$ & 0 & $1(9.1)$ & $1(6.7)$ & 0.64 \\
\hline Other ${ }^{\mathrm{a}}$ & $3(5.0)$ & $1(10.0)$ & $2(18.9)$ & 0 & 0.24 \\
\hline \multicolumn{6}{|l|}{ Isolated pathogens ${ }^{\mathrm{b}}$} \\
\hline Candida spp. & $34(94.4)$ & $10 / 10(100)$ & $10 / 11(90.1)$ & $14 / 15(93.3)$ & 0.49 \\
\hline Aspergillus spp. & $2(5.6)$ & 0 & $1 / 11(9.1)$ & $1 / 15(6.7)$ & \\
\hline Septic shock & $17(28.3)$ & $7(35.0)$ & $10(50.0)$ & 0 & 0.22 \\
\hline SOFA score $($ mean $\pm \mathrm{SD})$ & $6.8 \pm 3.2$ & $6.5 \pm 3.2$ & $8.1 \pm 2.8$ & $5.8 \pm 3.2$ & 0.06 \\
\hline Development of short-term hepatotoxicity & $6(10.0)$ & $2(10.0)$ & $2(10.0)$ & $2(10.0)$ & 1 \\
\hline In-hospital mortality & $22(36.6)$ & $8(40.0)$ & $9(45.0)$ & $5(25.0)$ & 0.39 \\
\hline $\begin{array}{l}\text { Bold value indicate } p<0.05 \\
A D \text { ascitic decompensation } \\
\text { a Hepatocellular carcinoma } \\
\text { b Overall, a pathogen was isolated in } 360\end{array}$ & & $.0 \%)$ & & & \\
\hline
\end{tabular}

No deaths were considered related to the antifungal drugs. Causes of death were mostly related to worsening of underlying disease (nine patients), invasive fungal infection (six patients).

Follow-up information was available for 30 patients until a median of 1.3 years after discharge. During the following year, no differences were observed between groups with respect to rate of re-hospitalization [50.0\% (6/ 12) for micafungin vs. $85.7 \%(6 / 7)$ for other echinocandins and $81.8 \%(9 / 11)$ for azoles, $p=0.23)]$ number of episodes of ascitic decompensation [(16.6\% (2/12) vs. $14.3 \%(1 / 7)$ vs. $27.3 \%(3 / 11)]$, gastrointestinal bleeding $(0 \%$ in each group), or mortality rate $[33.3 \%(4 / 12)$ vs. $28.7 \%(2 / 7)$ vs $36.3 \%(4 / 11)]$. Only 1 patient in the azoles group experienced LTLI with a new diagnosis of hepatocellular carcinoma 3 years after the index date.

\section{Risk Factors for Liver Injury}

We performed a univariate analysis in order to identify potential risk factors for STLI, including the following variables: age, other underlying conditions, severity of liver disease, septic shock, baseline liver and renal function, and length of antifungal treatment. The only variables associated with STLI were presence of septic shock at the time of antifungal therapy (66.7\% vs. $24.1 \%, p=0.04)$ and higher MELD score $(24.6 \pm 8.6$ vs $1.6 .9 \pm 6.8, \quad p=0.01)$ (Table 2). However, differences were not significant for any variables in the multivariate analysis. 
(A)

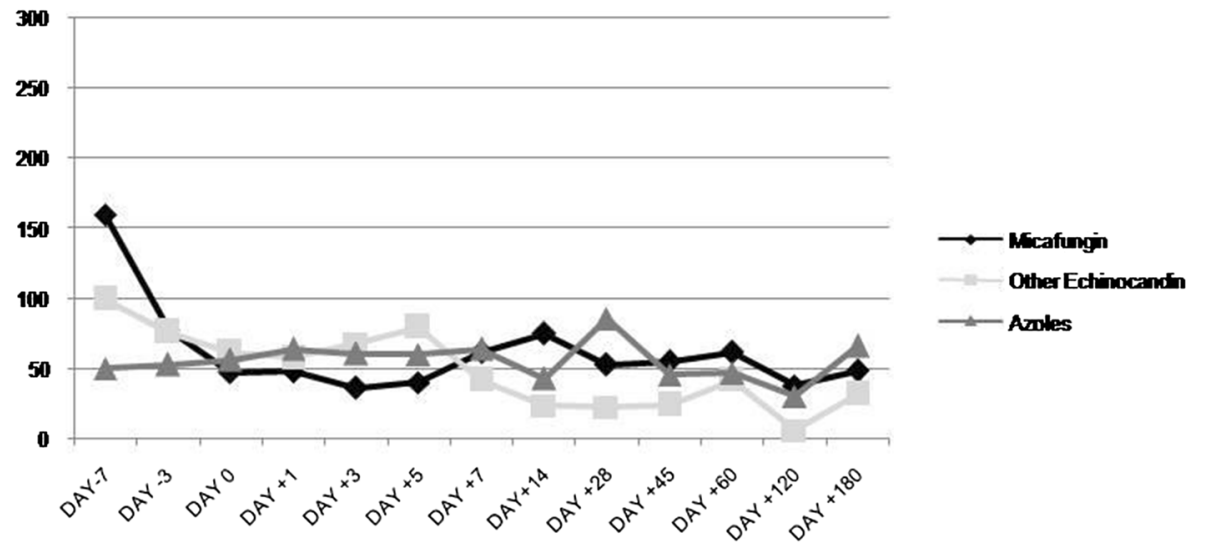

(B)

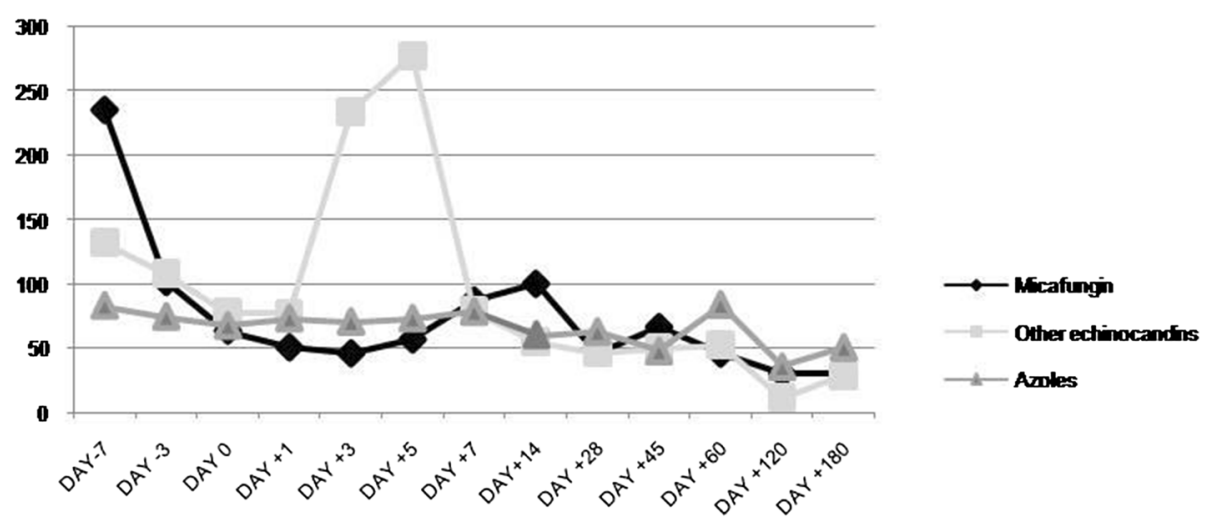

(C)

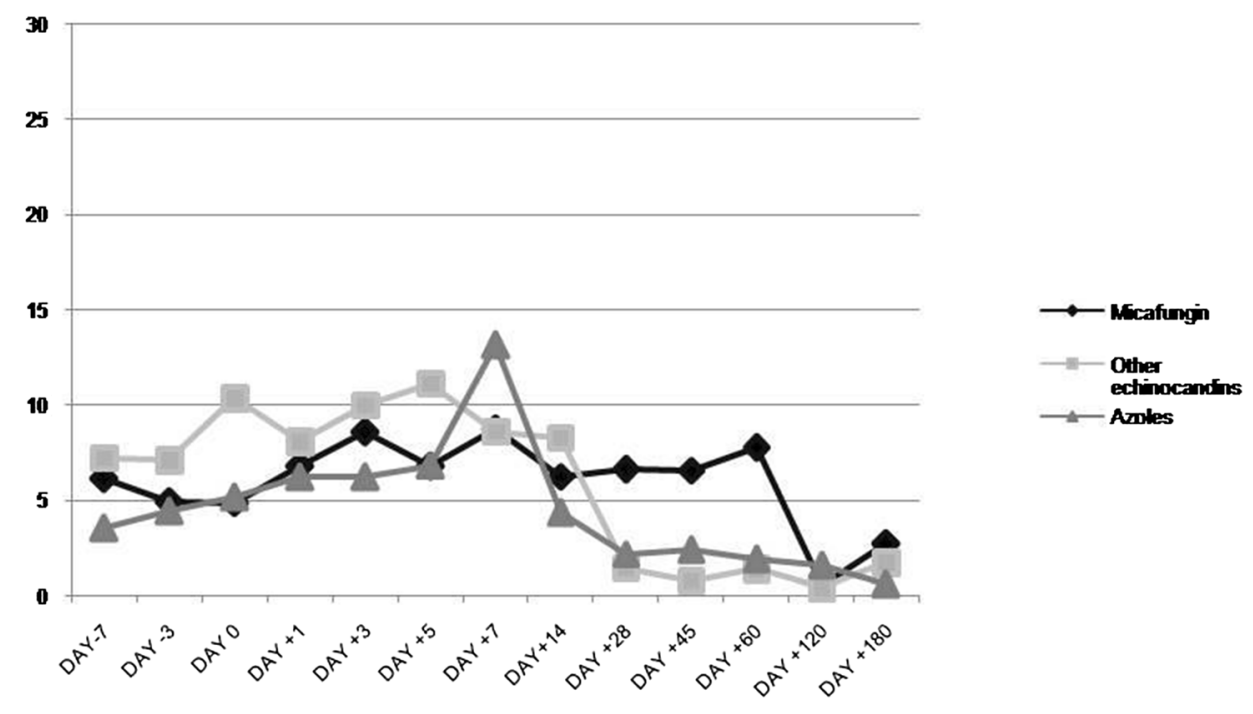

Fig. 1 Mean AST (a), ALT (b) and mean bilirubin (c) level according to specific study drug 
Table 2 Univariate models predicting short-term liver toxicity

\begin{tabular}{llll}
\hline Characteristics & $\begin{array}{l}\text { No liver injury } \\
\boldsymbol{n}=\mathbf{5 4}\end{array}$ & $\begin{array}{l}\text { Hepatotoxicity } \\
\boldsymbol{n}=\mathbf{6}\end{array}$ & $\boldsymbol{p}$ \\
\hline Age (years) (mean \pm SD) & $57.8 \pm 14.8$ & $61.5 \pm 13.1$ & 0.56 \\
Male sex & $42(77.8)$ & $3(50.0)$ & 0.15 \\
Severity of liver disease & & & 0.68 \\
Child B & $32(37.0)$ & $3(50)$ & 0.68 \\
Child C & $22(40.7)$ & $3(50)$ & 0.12 \\
Baseline child-pugh score & $9.0 \pm 1.4$ & $10.0 \pm 1.5$ & $\mathbf{0 . 0 0 1}$ \\
Baseline MELD score & $16.9 \pm 6.9$ & $24.9 \pm 8.5$ & 0.20 \\
Reason for starting AF therapy & & $4(66.7)$ & \\
Empirical therapy & $20(37.0)$ & $2(33.3)$ & $\mathbf{0 . 0 4}$ \\
Targeted therapy & $34(63.0)$ & $4(66.7)$ & 0.24 \\
Septic shock & $13(24.1)$ & $10.5 \pm 5.2$ & 1 \\
Length of AF treatment & $14.5 \pm 8.2$ & $2(33.3)$ & \\
Micafungin treatment & $18(33.3)$ & & \\
\hline
\end{tabular}

Significant $p$ values shown in bold

$S D$ standard deviation, $I C U$ intensive care unit, $A F$ antifungal

Table 3 Incidence of STLI according to baseline MELD score

\begin{tabular}{llll}
\hline $\begin{array}{l}\text { Meld } \\
\text { score }\end{array}$ & $\begin{array}{l}\text { Micafungin } \\
\boldsymbol{n}=\mathbf{2 0}\end{array}$ & $\begin{array}{l}\text { Other } \\
\text { echinocandins } \\
\boldsymbol{n}=\mathbf{2 0}\end{array}$ & $\begin{array}{l}\text { Azoles } \\
\boldsymbol{n}=\mathbf{2 0}\end{array}$ \\
\hline$<10$ & $0 / 1(0)$ & $0 / 0$ & $0 / 4$ \\
$10-20$ & $1 / 10(10.0)$ & $1 / 10(10.0)$ & $0 / 13$ \\
$>20$ & $1 / 9(11.1)$ & $1 / 10(10.0)$ & $2 / 3(66.7)$ \\
\hline
\end{tabular}

Given that only one patient had LTLI, univariate analysis was not performed to identify risk factors for long-term liver complications.

The incidence of STLI according to the baseline MELD score is reported in Table 3. When the baseline MELD score was $>20$, the incidence of STLI was significantly higher in patients with azoles $(2 / 3,66.6 \%)$ than in those treated with micafungin $(1 / 9,11.1 \%)$ or other ecchinocandins $(1 / 10 ; 10 \%)$. The median time between the index date and the development of STLI was 7 days (range 3-14 days).

\section{DISCUSSION}

To our knowledge, the present study is the first to show that, compared with other echinocandins or azoles, exposure to micafungin in patients with ESLD does not increase the risk of STLI or LTLI.

The incidence of IFI among patients with advanced liver disease has been reported to be as high as $10 \%[23,24]$, with a mortality rate up to $98 \%[2,5,25-27]$. In addition, liver disease has been found to be an independent risk factor for mortality [25], possibly because of abnormalities of the immune system [6, 28-30]. This risk is proportional to the level of hepatic impairment [5, 31].

The choice of antifungals in patients with ESLD is limited by a number of factors, including medical comorbidities, drug-drug 
interactions, and antifungal resistance [32], although the main factor limiting treatment is the hepatotoxicity of antifungal drugs [33]. Liposomal amphotericin B and azoles are both associated with a significant risk of hepatotoxicity $(27 \%)$ [21, 33-35]. Moreover, liposomal amphotericin B has been associated with an increasing risk of nephrotoxicity and infusionrelated reactions [36], whereas azoles have a limited spectrum of antifungal activity and can cause severe drug-drug interactions [37]. Thus, the use of alternative antifungal drugs for the treatment of IFIs in patients with pre-existing liver disease is of particular clinical relevance.

Echinocandins have an excellent safety profile and are promising agents for the treatment of IFI in patients with ESLD. Both anidulafungin and caspofungin have been studied for this indication, although information is mainly from patients with Child-Pugh A or B liver disease, while experience in Child-Pugh $C$ disease is very limited [7-11].

Micafungin has a broad in vitro spectrum, potent in vivo activity, a favorable safety profile, and excellent bioavailability, and is indicated for the treatment of invasive candidiasis [38, 39], esophageal candidiasis [40], and antifungal prophylaxis in patients with hematological disease [41].

Micafungin is generally safe in patients who do not have chronic liver disease, with no evidence of a greater risk of STLI than other antifungal drugs [38-41]. A systematic review and meta-analysis [21] showed that abnormal liver function test results during treatment with micafungin were observed in 3\% of the patients, with only $2.7 \%$ discontinuing treatment for hepatotoxicity. In a more recent study, no increased risk of short-term liver injury was observed in comparison to other antifungals (fluconazole, caspofungin, voriconazole and amphotericin B) in a cohort of pediatric and adult patients without chronic renal and liver conditions who received micafungin [15].

Evidence of hepatic toxicity in patients with chronic liver disease receiving micafungin is very limited but also generally reassuring [12-14]. Nevertheless, the relative magnitude of short-term liver risk compared to other antifungals in the ESLD population is less clear. Our data show that micafungin, in comparison to other echinocandins or azole therapy, did not incur a higher risk of hepatotoxicity in patients with ESLD. Indeed, the groups had similar rates of STLI and a comparable change in transaminase level during therapy. More specifically, the transaminase level remained stable or decreased during micafungin therapy, and discontinuation of micafungin due to its hepatic adverse effects was required in only one patient. Moreover, in our study, in comparison to fluconazole, micafungin and the other echinocandins were more commonly prescribed among patients with higher MELD score, which is by itself a risk factor for STLI.

As for LTLI, we found no major safety concerns relating the development of hepatic tumors during a follow-up period of more than 1 year. Preclinical data from animal studies reported the development of foci of altered hepatocytes and hepatocellular tumors in rats treated with high doses of micafungin for prolonged periods. Interestingly, although similar studies have never been performed for anidulafungin [42] or caspofungin [43], comparable results were also observed in long-term studies performed in animals receiving voriconazole [44] or fluconazole [45]. In the present study, we observed only one patient previously treated with azoles experiencing a new diagnosis of hepatocarcinoma during the follow-up period. We did not find evidence of liver tumors in any of the ESLD patients treated with micafungin, thus pointing to potential differences in tumor development between humans and rats. Our findings are consistent with the results from a pooled safety analysis including 3028 patients treated with micafungin [20] and support the absence of post-marketing reports of hepatic adenoma or carcinoma related to micafungin, despite more than 1,000,000 patients worldwide having received the drug.

There are several potential limitations of our study. First, its retrospective design and the relatively small number of patients included are the major weakness. However, patients were identified after checking more than 2000 patients in six large Spanish and Italian hospitals. Second, channeling bias is also likely since providers who are aware of the EMA warning 
would be expected to avoid prescription of micafungin in patients with a higher risk of developing STLI or LTLI. Third, although we used a predefined definition for hepatic injury, a direct relationship between hepatotoxicity and antifungals exposure could be difficult to evaluate, especially in high-risk groups of patients in which other variables (comorbidities, global degree of immunosuppression, other hepatotoxic drugs, toxins, etc.) may have played a role leading to over- or underreporting toxicity in our analysis. Fourth, although $\sim 70 \%$ of patients received antibiotics within the previous 1 year, we did not have data available regarding which antibiotics and how long they were administered. Such aspects may have also been confounders for liver events. Lastly, we did not count recurrent episodes of antifungal administration in this analysis, and the risk for STLI and LTLI could be different than that for the first episode.

Strengths of our study include its multicentric design and its optimal follow-up. To our knowledge, this study is the first in-depth report on short- and long-term safety of micafungin in patients with ESLD and its comparison with other echinocandins and azoles.

\section{CONCLUSIONS}

In conclusion, according to our study hypothesis, the administration of micafungin to patients with pre-existing Child-Pugh B or C ESLD was safe and, in routine clinical practice, did not imply a higher risk of developing shortor long-term liver injury.

\section{ACKNOWLEDGEMENTS}

We thank the participants of the study.

Funding. The present study was funded by the PROgrama MULtidisciplinar para la Gestión de Antifúngicos y la Reducción de Candidiasis Invasora (PROMULGA II Project), Instituto de Salud Carlos III Madrid Spain, and by the European Regional Development Fund (FEDER)
"A way of making Europe" (grant number PI13/ 01148). Antonio Vena is supported by a Rio Hortega grant from the Instituto de Salud Carlos III Madrid Spain, which is partially funded by the European Regional Development Fund (FEDER) "A way of making Europe" (grant number CM15/00181). No funding or sponsorship was received for the publication of this article. This study was supported by an independent medical grant from Astellas. The funders had no role in study design, data collection and analysis, decision to publish, or preparation of the manuscript.

Editorial Assistance. We would like to express our special thanks to Magdalena Salcedo for helping us with the preparation of the study design.

Authorship. All named authors meet the International Committee of Medical Journal Editors (ICMJE) criteria for authorship for this article, take responsibility for the integrity of the work as a whole, and have given their approval for this version to be published.

Disclosures. Matteo Bassetti has participated in advisory boards and/or received speaker honoraria from Achaogen, Angelini, Astellas, AstraZeneca, Bayer, Basilea, Cidara, Gilead, Menarini, MSD, Paratek, Pfizer, Roche, The Medicine Company, Shionogi, Tetraphase, VenatoRx and Vifor. Patricia Munoz is a consultant and/or speaker for Astellas, Gilead, Merck, Novartis and Pfizer and T2 Biosystems. Matteo Bassetti and Antonio Vena now belong to "Department of Health Sciences, Infectious Disease Clinic, University of Genoa and Hospital Policlinico San Martino-IRCCS, Genoa, Italy". Emilio Bouza, Francesco Menichetti, Maria Merelli, Santiago Grau, Jesús Fortun, María Isabel Sánchez, José María Aguado, Paloma Merino and Francisco Bonache have nothing to declare.

Compliance with Ethical Guidelines. The study was approved by the institutional review board of the coordinating center (Hospital General Universitario Gregorio Maranon MICRO.HGUGM.2014-017) and was in 
accordance with the declaration of Helsinki. Informed consent was deemed unnecessary due to the retrospective nature of the study.

Data Availability. The datasets generated during and/or analyzed during the current study are available from the corresponding author on reasonable request.

Open Access. This article is distributed under the terms of the Creative Commons Attribution-NonCommercial 4.0 International License (http://creativecommons.org/licenses/ by-nc/4.0/), which permits any noncommercial use, distribution, and reproduction in any medium, provided you give appropriate credit to the original author(s) and the source, provide a link to the Creative Commons license, and indicate if changes were made.

\section{REFERENCES}

1. Pilmis B, Puel A, Lortholary O, Lanternier F. New clinical phenotypes of fungal infections in special hosts. Clin Microbiol Infect. 2016;22(8):681-7.

2. Falcone M, Massetti AP, Russo A, Vullo V, Venditti M. Invasive aspergillosis in patients with liver disease. Med Mycol. 2011;49(4):406-13.

3. Theocharidou E, Agarwal B, Jeffrey G, Jalan R, Harrison D, Burroughs AK, et al. Early invasive fungal infections and colonization in patients with cirrhosis admitted to the intensive care unit. Clin Microbiol Infect. 2016;22(2):189 (e1-7).

4. Hassan EA, Abd El-Rehim AS, Hassany SM, Ahmed AO, Elsherbiny NM, Mohammed MH. Fungal infection in patients with end-stage liver disease: low frequency or low index of suspicion. Int J Infect Dis. 2014;23:69-74.

5. Bartoletti M, Giannella M, Caraceni P, Domenicali M, Ambretti S, Tedeschi S, et al. Epidemiology and outcomes of bloodstream infection in patients with cirrhosis. J Hepatol. 2014;61(1):51-8.

6. Russo A, Giuliano S, Vena A, Lucidi C, Falcone M, Raponi $G$, et al. Predictors of mortality in nonneutropenic patients with invasive pulmonary aspergillosis: does galactomannan have a role? Diagn Microbiol Infect Dis. 2014;80(1):83-6.
7. Spriet I, Meersseman W, Annaert P, de Hoon J, Willems L. Pharmacokinetics of caspofungin in a critically ill patient with liver cirrhosis. Eur J Clin Pharmacol. 2011;67(7):753-5.

8. van der Elst KC, Bruggemann RJ, Rodgers MG, Alffenaar JW. Plasma concentrations of caspofungin at two different dosage regimens in a patient with hepatic dysfunction. Transpl Infect Dis. 2012;14(4): 440-3.

9. Mistry GC, Migoya E, Deutsch PJ, Winchell G, Hesney M, Li S, et al. Single- and multiple-dose administration of caspofungin in patients with hepatic insufficiency: implications for safety and dosing recommendations. J Clin Pharmacol. 2007;47(8):951-61.

10. Dowell JA, Stogniew M, Krause D, Damle B. Anidulafungin does not require dosage adjustment in subjects with varying degrees of hepatic or renal impairment. J Clin Pharmacol. 2007;47(4):461-70.

11. Montesinos P, Rodriguez-Veiga R, Martinez-Cuadron D, Boluda B, Navarro I, Vera B, et al. Treatment of invasive fungal disease using anidulafungin alone or in combination for hematologic patients with concomitant hepatic or renal impairment. Rev Iberoam Micol. 2015;32(3):185-9.

12. Luque S, Campillo N, Alvarez-Lerma F, Ferrandez O, Horcajada JP, Grau S. Pharmacokinetics of micafungin in patients with pre-existing liver dysfunction: a safe option for treating invasive fungal infections. Enferm Infecc Microbiol Clin. 2016;34(10):652-4.

13. Undre N, Pretorius B, Stevenson P. Pharmacokinetics of micafungin in subjects with severe hepatic dysfunction. Eur J Drug Metab Pharmacokinet. 2015;40(3):285-93.

14. Hebert MF, Smith HE, Marbury TC, Swan SK, Smith WB, Townsend RW, et al. Pharmacokinetics of micafungin in healthy volunteers, volunteers with moderate liver disease, and volunteers with renal dysfunction. J Clin Pharmacol. 2005;45(10): 1145-52.

15. Schneeweiss S, Carver PL, Datta K, Galar A, Johnson MD, Johnson MG, et al. Short-term risk of liver and renal injury in hospitalized patients using micafungin: a multicentre cohort study. J Antimicrob Chemother. 2016;71(10):2938-44.

16. Neofytos D, Huang YT, Cheng K, Cohen N, Perales MA, Barker J, et al. Safety and efficacy of intermittent intravenous administration of high-dose micafungin. Clin Infect Dis. 2015;61(Suppl 6): S652-61. 
17. Heimann SM, Vehreschild MJ, Meintker L, Heinz $\mathrm{W}$, Schroeder T, von Bergwelt-Baildon $\mathrm{M}$, et al. Different doses of micafungin for prophylaxis of invasive fungal diseases in hemato-oncological high-risk patients: a web-based non-interventional trial in four large university hospitals in Germany. Transpl Infect Dis. 2014;16(6):968-74.

18. Valerio M, Munoz P, Bouza E. Liver toxicity of micafungin. Is this drug safe? Enferm Infecc Microbiol Clin. 2011;29(Suppl 2):29-32.

19. Cornely OA, Marty FM, Stucker F, Pappas PG, Ullmann AJ. Efficacy and safety of micafungin for treatment of serious Candida infections in patients with or without malignant disease. Mycoses. 2011;54(6):e838-47.

20. Cornely OA, Pappas PG, Young JA, Maddison P, Ullmann AJ. Accumulated safety data of micafungin in therapy and prophylaxis in fungal diseases. Expert Opin Drug Saf. 2011;10(2):171-83.

21. Wang JL, Chang CH, Young-Xu Y, Chan KA. Systematic review and meta-analysis of the tolerability and hepatotoxicity of antifungals in empirical and definitive therapy for invasive fungal infection. Antimicrob Agents Chemother. 2010;54(6): 2409-19.

22. Desmet VJ, Gerber M, Hoofnagle JH, Manns M, Scheuer PJ. Classification of chronic hepatitis: diagnosis, grading and staging. Hepatology. 1994;19(6):1513-20.

23. Lin $\mathrm{LN}, \mathrm{Zhu} \mathrm{Y}$, Che FB, Gu JL, Chen JH. Invasive fungal infections secondary to acute-on-chronic liver failure: a retrospective study. Mycoses. 2013;56(4):429-33.

24. Karvellas CJ, Pink F, McPhail M, Austin M, Auzinger $\mathrm{G}$, Bernal W, et al. Bacteremia, acute physiology and chronic health evaluation II and modified end stage liver disease are independent predictors of mortality in critically ill nontransplanted patients with acute on chronic liver failure. Crit Care Med. 2010;38(1):121-6.

25. Garcia-Vidal C, Peghin M, Cervera C, Gudiol C, Ruiz-Camps I, Moreno A, et al. Causes of death in a contemporary cohort of patients with invasive aspergillosis. PLoS One. 2015;10(3):e0120370.

26. Chen J, Yang Q, Huang J, Li L. Clinical findings in 19 cases of invasive pulmonary aspergillosis with liver cirrhosis. Multidiscip Respir Med. 2014;9(1):1.

27. Wu Z, Ling Z, Shao F, Sheng J, Li L. Invasive pulmonary aspergillosis in patients with acute-onchronic liver failure. J Int Med Res. 2012;40(5): 1958-65.
28. Albillos A, Lario M, Alvarez-Mon M. Cirrhosis-associated immune dysfunction: distinctive features and clinical relevance. J Hepatol. 2014;61(6): 1385-96.

29. Ferri C, Antonelli A, Mascia MT, Sebastiani M, Fallahi P, Ferrari D, et al. HCV-related autoimmune and neoplastic disorders: the HCV syndrome. Dig Liver Dis. 2007;39(Suppl 1):S13-21.

30. Gomez F, Ruiz P, Schreiber AD. Impaired function of macrophage Fc gamma receptors and bacterial infection in alcoholic cirrhosis. $\mathrm{N}$ Engl J Med. 1994;331(17):1122-8.

31. Theocharidou E, Pieri G, Mohammad AO, Cheung M, Cholongitas E, Agarwal B, et al. The Royal Free Hospital score: a calibrated prognostic model for patients with cirrhosis admitted to intensive care unit. Comparison with current models and CLIFSOFA score. Am J Gastroenterol. 2014;109(4): 554-62.

32. Pfaller MA, Messer SA, Woosley LN, Jones RN, Castanheira M. Echinocandin and triazole antifungal susceptibility profiles for clinical opportunistic yeast and mold isolates collected from 2010 to 2011: application of new CLSI clinical breakpoints and epidemiological cutoff values for characterization of geographic and temporal trends of antifungal resistance. J Clin Microbiol. 2013;51(8): 2571-81.

33. Tverdek FP, Kofteridis D, Kontoyiannis DP. Antifungal agents and liver toxicity: a complex interaction. Expert Rev Anti Infect Ther. 2016;14(8): 765-76.

34. Denning DW, Ribaud P, Milpied N, Caillot D, Herbrecht R, Thiel E, et al. Efficacy and safety of voriconazole in the treatment of acute invasive aspergillosis. Clin Infect Dis. 2002;34(5):563-71.

35. Potoski BA, Brown J. The safety of voriconazole. Clin Infect Dis. 2002;35(10):1273-5.

36. Ullmann AJ, Sanz MA, Tramarin A, Barnes RA, Wu W, Gerlach BA, et al. Prospective study of amphotericin $\mathrm{B}$ formulations in immunocompromised patients in four European countries. Clin Infect Dis. 2006;43(4):e29-38.

37. Andes D, Azie N, Yang H, Harrington R, Kelley C, Tan RD, et al. Drug-drug interaction associated with mold-active triazoles among hospitalized patients. Antimicrob Agents Chemother. 2016;60(6):3398-406.

38. Kuse ER, Chetchotisakd P, da Cunha CA, Ruhnke M, Barrios C, Raghunadharao D, et al. Micafungin versus liposomal amphotericin B for candidaemia and invasive candidosis: a phase III randomised 
double-blind trial. Lancet. 2007;369(9572): 1519-27.

39. Pappas PG, Rotstein CM, Betts RF, Nucci M, Talwar $\mathrm{D}$, De Waele JJ, et al. Micafungin versus caspofungin for treatment of candidemia and other forms of invasive candidiasis. Clin Infect Dis. 2007;45(7):883-93.

40. de Wet NT, Bester AJ, Viljoen JJ, Filho F, Suleiman JM, Ticona E, et al. A randomized, double blind, comparative trial of micafungin (FK463) vs fluconazole for the treatment of oesophageal candidiasis. Aliment Pharmacol Ther. 2005;21(7): 899-907.

41. van Burik JA, Ratanatharathorn V, Stepan DE, Miller CB, Lipton JH, Vesole DH, et al. Micafungin versus fluconazole for prophylaxis against invasive fungal infections during neutropenia in patients undergoing hematopoietic stem cell transplantation. Clin Infect Dis. 2004;39(10):1407-16.

42. EraxisTM (anidulafungin) for injection: prescribing information. Pfizer Inc, 2009.

43. Cancidas (caspofungin acetate) prescribing information. Merck \& co. Inc.

44. Vfend (voriconazole): prescribing information. Pfizer, Inc, 2010.

45. Diflucan (fluconazole): prescribing information. Pfizer Inc, 2010. 